\title{
Jungbrunnen-Effekt
}

\section{Sport und Darben hält Gehirne fit}

\begin{abstract}
Mit Sport und Ernährungsumstellung altersbedingten Veränderungen des Hirns vorbeugen und therapieren? Zusammen mit ersten Fortschritten bei krankheitsverzögernden Medikamenten bieten Studien zum Einfluss des Lebensstils bei Demenz Grund zur Hoffnung hinsichtlich der aktuellen demografischen Entwicklung.
\end{abstract}

Neben der symptomatisch pharmakologischen Therapie sind einfache „Lebensstilmodifikationen“ ein Ansatzpunkt der Forschung zur Prävention und Therapie altersassoziierter neurodegenerativer Erkrankungen, wie Demenz vom Alzheimer Typ und idiopathischem Parkinson-Syndrom. Die Zunahme dieser
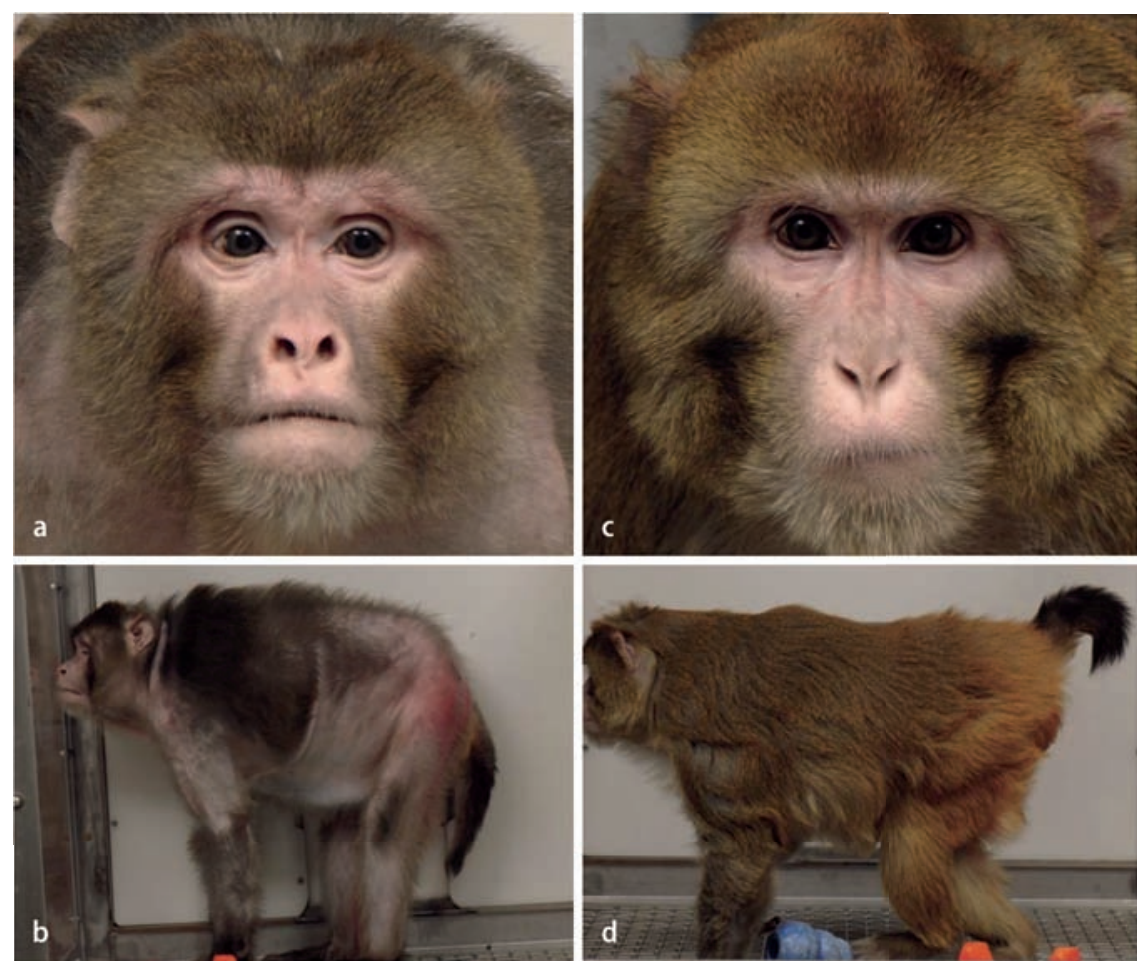

Abb. 1 Erscheinungsbild zweier altersgleicher Rhesusaffen bei einer Kalorienrestriktionsstudie. a, b Affe unter uneingeschränkter Ernährung (Kontroll-Tiere); c, d deutlich fitteres Tier bei 30\%iger Kalorienrestriktion. [Mit freundlicher Genehmigung aus Colman et al 2009, Science 325(5937): 201] triktion und Nahrungsergänzung mit Omega-3-Fettsäuren Alterserscheinungen und degenerative Prozesse positiv beeinflussen, berichten Dr. Barbara Steiner und Kollegen der Berliner Charité im „Nervenarzt“.

\section{Nervenzellen ersetzen}

Mit verschiedenen physiologischen Stimuli kann die Neubildung und Lebensdauer von Nervenzellen gesteigert werden. Zum einen fördert körperliche Aktivität neben der Motorik die Gedächtnisleistungen im gesunden, aber auch neurodegenerativ veränderten Hirn. Regelmäßiger Sport im Alter kann das Risiko einer Demenz verringern. In einer US-Studie konnten aktive Senioren, verglichen mit weniger aktiven Probanden, mit dreimal Sport pro Woche ihr Demenzrisiko um 34\% reduzieren.

\section{Weniger altersassoziierte Krankheiten}

Zum anderen spielt auch die Ernährung eine große Rolle. Eine 30\%ige Energierestriktion führt zu einer Zunahme der grauen Substanz in gedächtnisrelevanten Hirnarealen. Die älteren Probanden zeigten verbesserte kognitive Leistungen.

Zahlreiche Tierstudien bestätigen diesen "Jungbrunnen-Effekt" (• Abb. 1). Rhesusaffen sind bei restriktiver Diät allgemein fitter und zeigen einen geringeren Abbau grauer Substanz. Außerdem leiden die Tiere auch seltener unter anderen altersassoziierten Krankheiten, wie Diabetes mellitus Typ II, kardiovaskulären Erkrankungen und Malignomen. (Melanie Goldschmidt)

Nervenarzt 2011, 82:1566 